\title{
Wear maps for TiC composite based coatings deposited on 303 stainless steel
}

\author{
G. Rasool and M.M. Stack \\ Department of Mechanical and Aerospace Engineering \\ University of Strathclyde \\ James Weir Building \\ 75 Montrose St., \\ Glasgow \\ G1 1XJ
}

\begin{abstract}
Dry sliding wear (pin-on-disc) tests were carried out under ambient conditions at room temperature for TiC coated and uncoated 303 stainless steel, using alumina as a counterface. The composite coating which was developed by Tungsten Inert Gas (TIG) methods increased the surface hardness of the substrate and the sliding wear resistance of the substrate. Wear maps for both uncoated and coated materials were developed on the basis of tests results. These maps show that the mild wear regime for the composite coating extended to a higher range of sliding speeds and normal loads, than for the uncoated steel. The differences in wear mechanisms as identified on the wear maps for both coated and uncoated steel are addressed in this paper.
\end{abstract}

Keywords: dry sliding wear, pin-on-disc, uncoated, TiC composite coatings, wear maps.

\section{Introduction}

Due to its low hardness and austenitic/ferritic structure, the wear resistance of austenitic/ferritic stainless steel can limit its tribological application [1-2]. Coatings deposited on the surfaces of different substrates susceptible to wear, increase the operating life and range of conditions for which they may be used. In tribo-engineering applications, especially where components undergo sliding wear, steels may exhibit poor tribological properties such as low sliding wear resistance, fluctuating friction, delamination wear, ploughing wear, and plastic deformation.

Prediction of wear resistance of steels is approached with some difficulty as for example, the effects of many variables on the wear mechanisms are not well understood. For example, no simple relationship between hardness and wear resistance of materials can be formulated [3], [4]. Summarising the significant investigations carried out to date, wear mechanisms of steel involve adhesion, oxidation, plastic deformation, delamination of material, strain hardening, generation of surface and sub-surface cracks and associated structural changes [3]. 
In studies of the sliding wear behaviour of 303 stainless steel, it was found that there was significant material transfer onto the alumina ball during sliding in a similar manner to that observed during the study of friction and wear thresholds of alumina- chromium steel pairs sliding at high speeds in dry conditions [5]. It was observed that uncoated substrate showed very poor resistance to wear against alumina.

Titanium carbide coatings have found widespread application owing to their excellent hardness, at both room and elevated temperatures [6-8]. In some situations, a ceramic coating decreases the coefficient of friction during dry sliding, thereby resulting in decreased temperature rise and reduced adhesion at the interface, both of which promote the decrease in wear rate [7-9].

The sliding friction and wear behaviour of a ceramic coating depends upon the characteristics of the coating such as hardness, thickness, internal stress level, and load bearing capacity. When a coating cools from the high temperature of the deposition process, the internal stress within the coating is generally compressive. The compressive stress reduces the extent of surface fracture and thus increases sliding wear resistance of the coated surface $[6,10]$. There is also shear stress induced between the coating and substrate. This stress promotes spalling of the coating during sliding wear [7]. The ability of a coating-substrate system to withstand such stresses without spalling or cohesion failure of the coating is referred to as its loadbearing capacity [10 \& 11]. A higher load-bearing capacity has been attributed to increased sliding wear resistance $[10 \& 11]$. Several wear mechanisms have been proposed for different coating-substrate systems. These are ploughing, micro-polishing, cohesive failure or fragmentation, spalling [10 \& 11], flake formation [12], removal of hard particle phase and binder extrusion [9]. Kitsunai et al. [12] have demonstrated that the wear mechanisms change with the severity of contact condition. However, in many cases, the conditions and regimes where the coating retains integrity are not well understood.

In the present study, the effects of applied load and sliding speed on the wear behaviour of 303SS uncoated and TiC composite coated 303 SS steel against alumina have been investigated. Regimes of wear have been identified for the coated and uncoated materials. Wear maps have been developed to study and predict the wear behaviour of 303SS uncoated and $303 \mathrm{SS}$ base $\mathrm{TiC}$ composite coating against alumina.

\section{Experimental conditions}

The experiments were carried out under ambient conditions at room temperature for dry sliding wear in pin-on-disc test method on CSM Tribometer for both uncoated and coated materials. The wear rate of 303SS uncoated and 303SS base TiC composite coating was measured against an alumina $\left(99.6 \% \mathrm{Al}_{2} \mathrm{O}_{3}\right.$, hardness $\left.1800 \mathrm{HV}\right)$ ball of diameter $3 \mathrm{~mm}$ sliding 
against the flat $303 \mathrm{SS}$ uncoated and $303 \mathrm{SS}$ base TiC composite coating disk. The ball was rigidly held at the contacting face of the pin. Sliding speeds were 3, 7, 11 and $15 \mathrm{cms}^{-1}$ and normal loads increased in increments of $2 \mathrm{~N}$ from to $10 \mathrm{~N}$, with the wear track diameter being $6 \mathrm{~mm}$. The test duration was calculated to ensure a constant sliding distance $500 \mathrm{~m}$ for the range of sliding speeds. The total number of revolutions was 26526 for each test. An analytical balance with accuracy of $0.01 \mathrm{mg}$ was used to evaluate mass loss following exposure. The wear rates were estimated by dividing the mass loss by the sliding distance. SEM and EDX analyses were carried out following exposure in order to identify the predominant wear mechanisms for the conditions.

\subsection{Materials}

2.1.1. The 303 stainless steel composition is shown on Table 1, shows a high proportion of $\mathrm{Cr}$ $(18.7 \%)$ and $\mathrm{Ni}(7.8 \%)$, Fig. 1. The hardness values of the 303 stainless steel and Alumina counterface were $172 \mathrm{HV} 10$ and Alumina $1800 \mathrm{HV}$ respectively.

Table 1. Composition of the 303

stainless steel disk

\begin{tabular}{|l|l|l|l|}
\hline Element wt. \% & 303 stainless steel & Element wt. \% & 303 stainless steel \\
\hline Ti & $0.201 \%$ & Co & $0.254 \%$ \\
\hline V & $0.207 \%$ & Ni & $7.76 \%$ \\
\hline Cr & $18.7 \%$ & Cu & $0.188 \%$ \\
\hline Mn & $1.44 \%$ & Ag & $0.104 \%$ \\
\hline Fe & $71.1 \%$ & Mo & $0.0548 \%$ \\
\hline
\end{tabular}
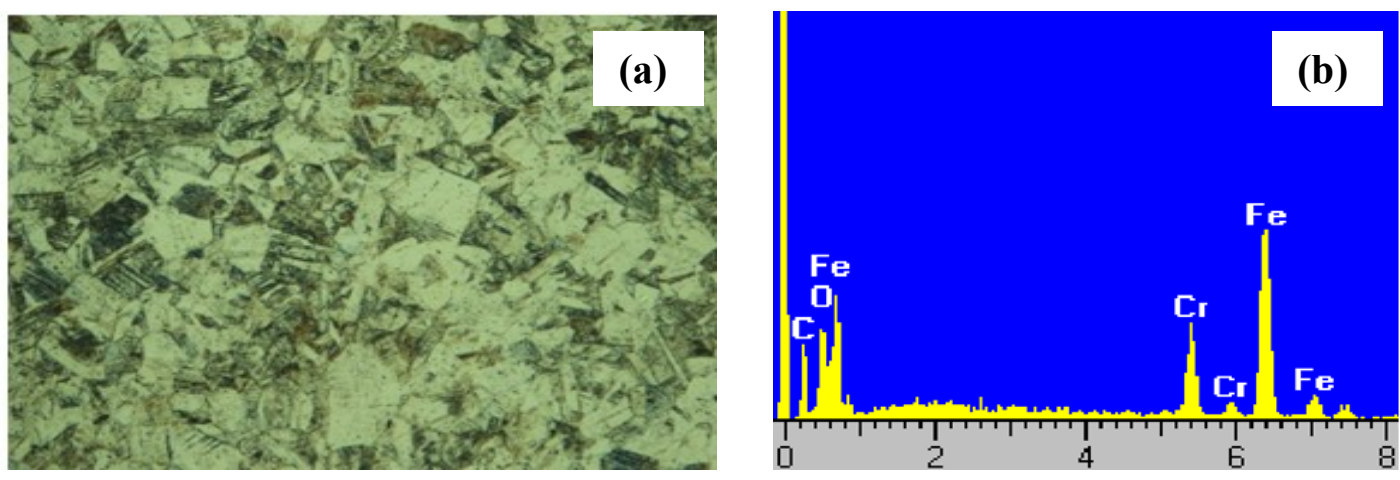

Fig. 1. a) Microstructure of 303 stainless steel 200X and b) EDX analysis of 303 stainless steel

2.2. The hardness values of the 303 stainless steel base $\mathrm{TiC}$ coatings and Alumina counterface were 347 HV10 and Alumina 1800 HV respectively. 


\subsection{Coating methods}

The TiC ceramic powder (of 99.5\% purity) and with nominal size between 45 and 100 micron was supplied by Meterion Inc. USA was used as the reinforcing powder throughout this experiment. The $303 \mathrm{SS}$ substrate was hydraulically sheared to the dimension of $75 \mathrm{x} 75 \mathrm{x}$ $5 \mathrm{~mm}$ and grounded using emery paper followed by degreasing them using acetone. TiC particulates of $1 \mathrm{mg} / \mathrm{mm}^{2}$ mixed with PVA binder were evenly spread on the cleaned substrate surface. To remove the moisture, the prepared samples were dried in the oven at $80^{\circ} \mathrm{C}$ for an hour before melting process. Metal matrix composite melt tracks were produced using TIG 165 machine with a $2.4 \mathrm{~mm}$ in diameter of tungsten thoriated electrode. A working distance of $1 \mathrm{~mm}$ was measured at the end of electrode tip to the surface of dried coating before the melting commenced. The input energy of $30 \mathrm{~V}$ at 90 ampere with the table travelling speed at $2 \mathrm{~mm} / \mathrm{sec}$ was used to produce $50 \%$ overlapped tracks as shown in Fig. 1. These overlapped/multi-pass tracks were produced in one single direction until the melt layers cover the total area of $75 \times 75 \mathrm{~mm}$. The direction and distance of travel were both controlled using simple numerical control technique. TIG melting efficiency is considered to be at $48 \%$ [13]. The samples were shielded using argon gas to prevent excessive oxidation. The average thickness of the coating was $0.5 \mathrm{~mm}$ after grinding.

\subsubsection{Optical Micrograph and EDX analysis of the 303SS base TiC composite coating}
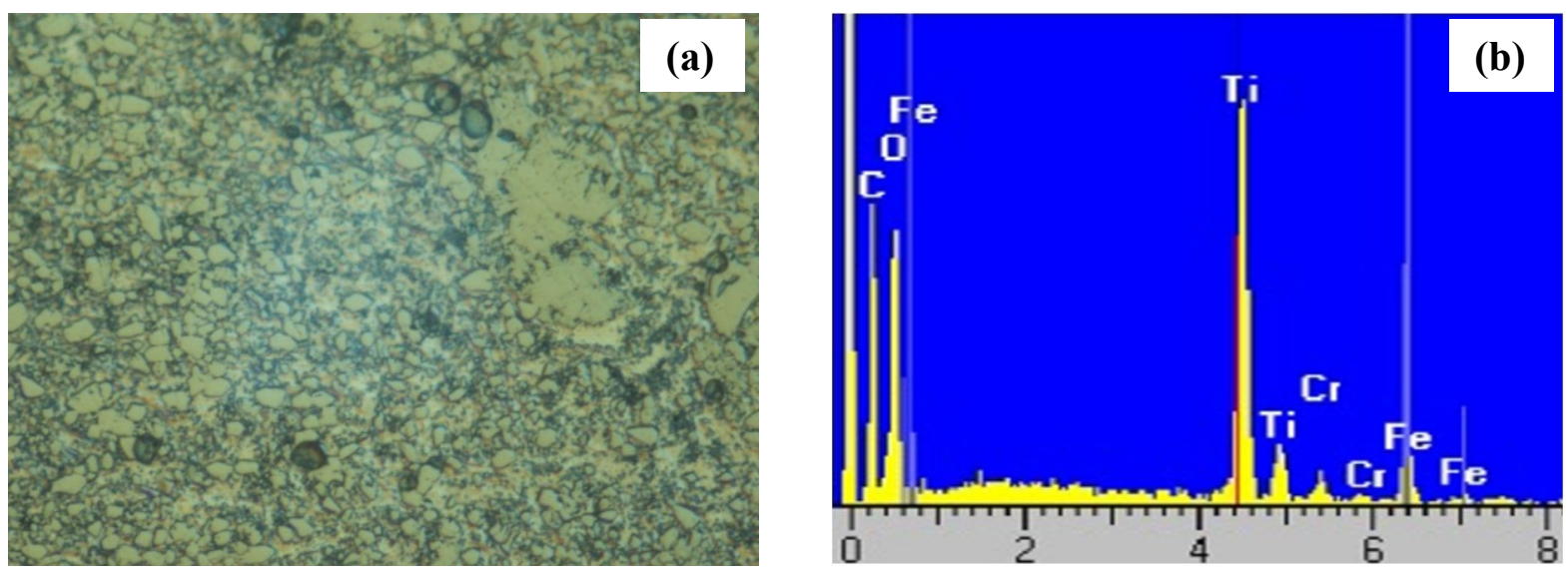

Fig. 2. a) Microstructure of 303 stainless steel base TiC coating surface magnification X500 and b) the EDX analysis of the 303 stainless steel base TiC coating

Table 2. The composition of the 303 stainless steel base TiC coating disk surface

Element Element \%

$\begin{array}{llll}\text { 3. W } & \text { Ti K } & 74.05 & \\ \text { 3.1. } & \text { Cr K } & 7.55 & \text { ounterface } \\ & \text { Fe K } & \mathbf{1 8 . 4 0} & \end{array}$



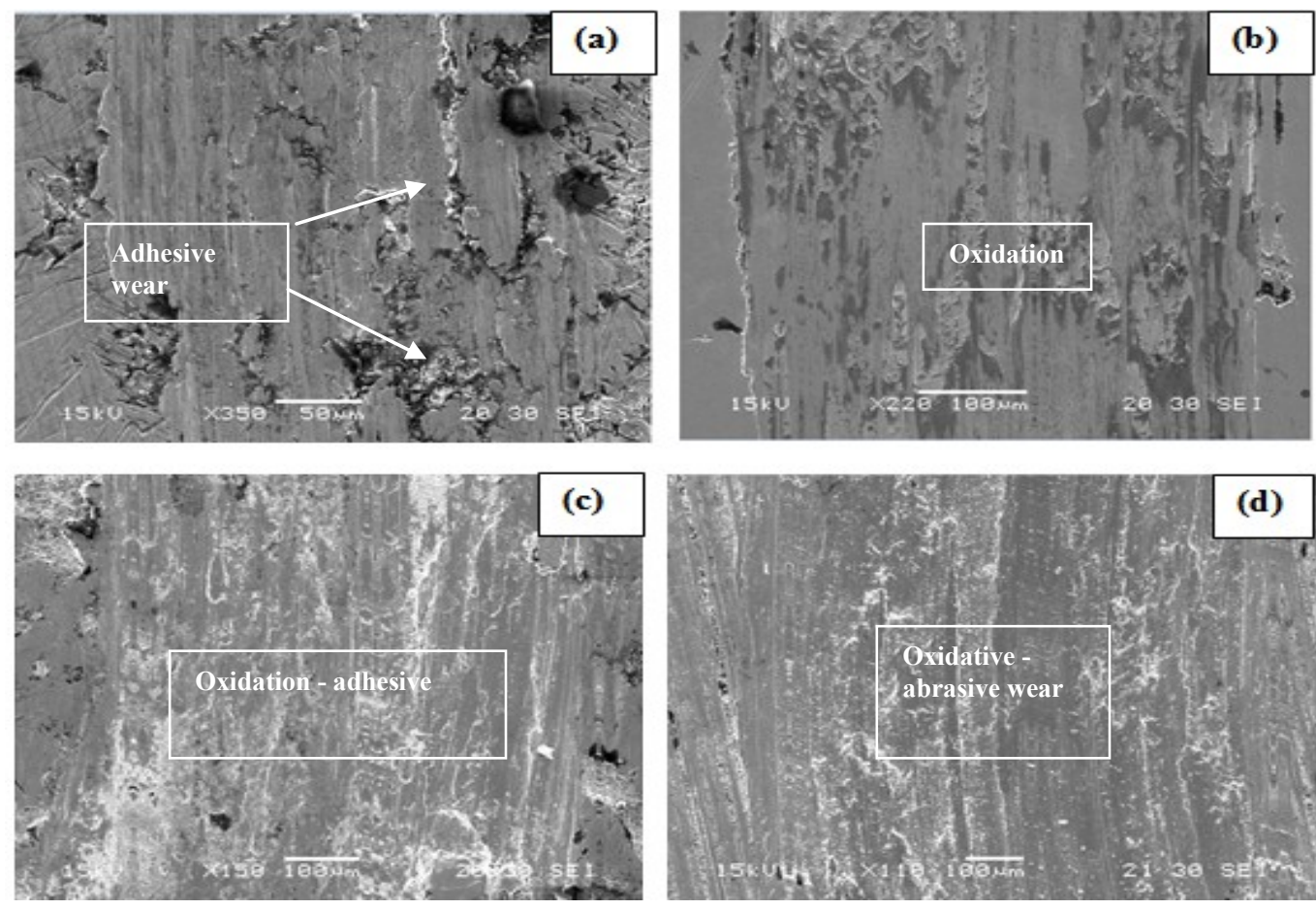

Fig. 3. SEM micrograph of the wear tracks, a) $2 \mathrm{~N}$ normal load and $3 \mathrm{~cm} . \mathrm{s}^{-1}$ sliding speed, b) $4 \mathrm{~N}$ normal load and $7 \mathrm{~cm} \cdot \mathrm{s}^{-1}$ sliding speed, c) $4 \mathrm{~N}$ normal load and $11 \mathrm{~cm} \cdot \mathrm{s}^{-1}$ sliding speed and d) $8 \mathrm{~N}$ normal load and $15 \mathrm{~cm} . \mathrm{s}^{-1}$ sliding speed
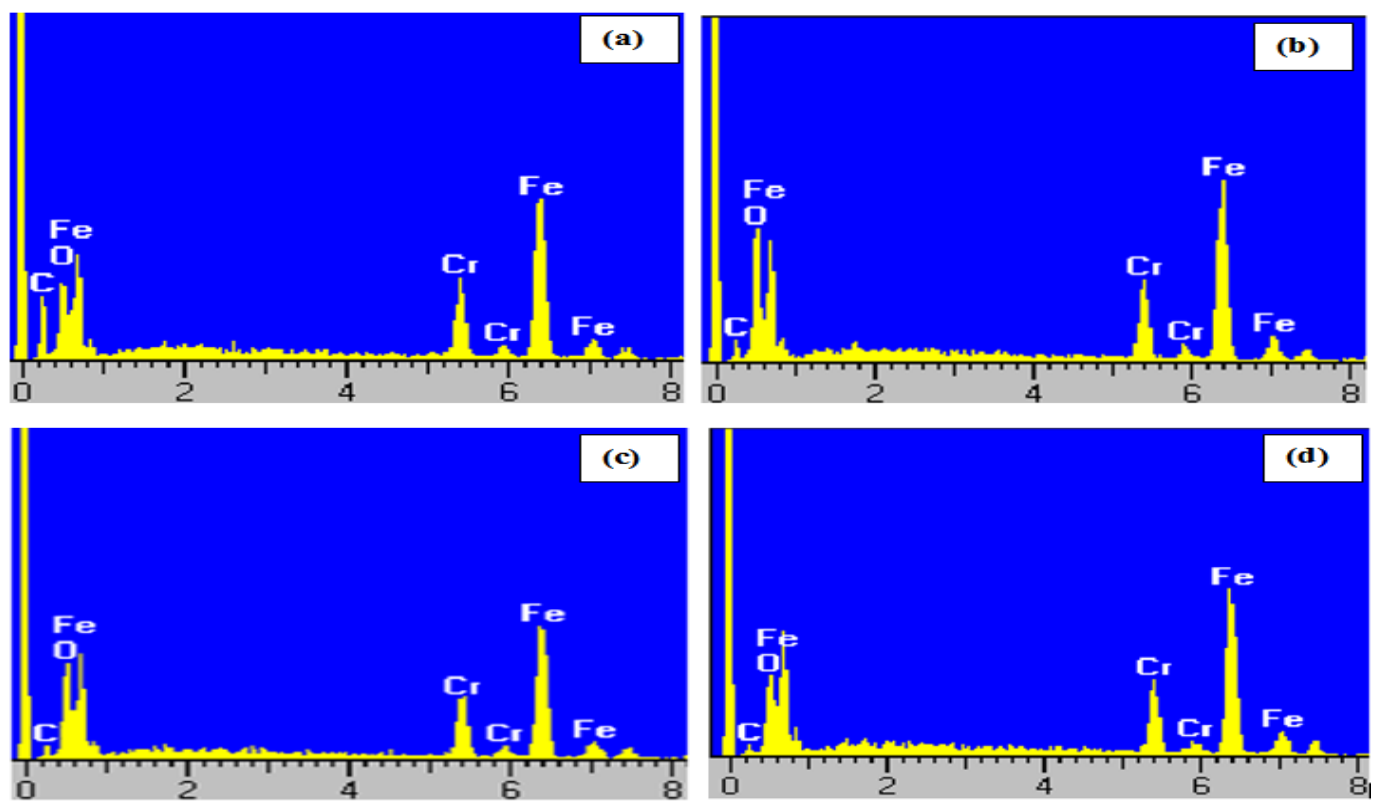

Fig. 4. EDX analysis of the wear tracks, a) $2 \mathrm{~N}$ normal load and $3 \mathrm{~cm} . \mathrm{s}^{-1}$ sliding speed, b) $4 \mathrm{~N}$ normal load and 7 $\mathrm{cm} . \mathrm{s}^{-1}$ sliding speed, c) $4 \mathrm{~N}$ normal load and $11 \mathrm{~cm} . \mathrm{s}^{-1}$ sliding speed and d) $8 \mathrm{~N}$ normal load and $15 \mathrm{~cm} . \mathrm{s}^{-1}$ sliding speed

Table 3. Wear rate of 303stainless steel against alumina at constant sliding speeds and various normal loads 


\begin{tabular}{|l|l|l|l|l|}
\hline Normal load $(\mathrm{N})$ & $\begin{array}{l}\text { Wear rate }\left(\mathrm{g} \cdot \mathrm{m}^{-1}\right) \\
\mathrm{x} 10^{-7} \text { at } 3 \mathrm{~cm} \cdot \mathrm{s}^{-1}\end{array}$ & $\begin{array}{l}\text { Wear rate }\left(\mathrm{g} \cdot \mathrm{m}^{-1}\right) \\
\mathrm{x} 10^{-7} \text { at } 7 \mathrm{~cm} \cdot \mathrm{s}^{-1}\end{array}$ & $\begin{array}{l}\text { Wear rate }\left(\mathrm{g} \cdot \mathrm{m}^{-1}\right) \\
\times 10^{-7} \text { at } 11 \mathrm{~cm} \cdot \mathrm{s}^{-1}\end{array}$ & $\begin{array}{l}\text { Wear rate }\left(\mathrm{g} \cdot \mathrm{m}^{-1}\right) \\
\mathrm{x} 10^{-7} \text { at } 15 \mathrm{~cm} \cdot \mathrm{s}^{-1}\end{array}$ \\
\hline 2 & 93 & 219 & 63 & 93 \\
\hline 4 & 44 & 83 & 167 & 174 \\
\hline 6 & 178 & 495 & 186 & 160 \\
\hline 8 & 288 & 422 & 259 & 275 \\
\hline 10 & 394 & 1429 & 342 & 599 \\
\hline
\end{tabular}

Table 4. Wear rate of 303 stainless steel against alumina at constant normal loads and various sliding speeds

\begin{tabular}{|l|l|l|l|l|l|l|}
\hline $\begin{array}{l}\text { Sliding speed } \\
\left(\mathrm{cm} \cdot \mathrm{s}^{-1}\right)\end{array}$ & $\begin{array}{l}\text { Wear rate } \\
\left(\mathrm{g} \cdot \mathrm{m}^{-1}\right) \times 10^{-7} \\
\text { at } 2 \mathrm{~N}\end{array}$ & $\begin{array}{l}\text { Wear rate } \\
\left(\mathrm{g} \cdot \mathrm{m}^{-1}\right) \times 10^{-7} \\
\text { at } 4 \mathrm{~N}\end{array}$ & $\begin{array}{l}\text { Wear rate } \\
\left(\mathrm{g} \cdot \mathrm{m}^{-1}\right) \\
\text { at } 6 \mathrm{~N}\end{array}$ & $\begin{array}{l}\text { Wear rate } \\
\left(\mathrm{g} \cdot \mathrm{m}^{-1}\right) \times 10^{-7} \\
\text { at } 8 \mathrm{~N}\end{array}$ & $\begin{array}{l}\text { Wear rate } \\
\left(\mathrm{g} \cdot \mathrm{m}^{-1}\right) \\
\text { at } 10 \mathrm{~N}\end{array}$ & $\begin{array}{r}\text { x } 10^{-7} \\
\hline 3\end{array}$ \\
\hline 93 & 44 & 178 & 288 & 394 \\
\hline 7 & 219 & 83 & 495 & 422 & 1429 \\
\hline 11 & 63 & 167 & 186 & 259 & 342 \\
\hline 15 & 93 & 174 & 160 & 275 & 599 \\
\hline
\end{tabular}
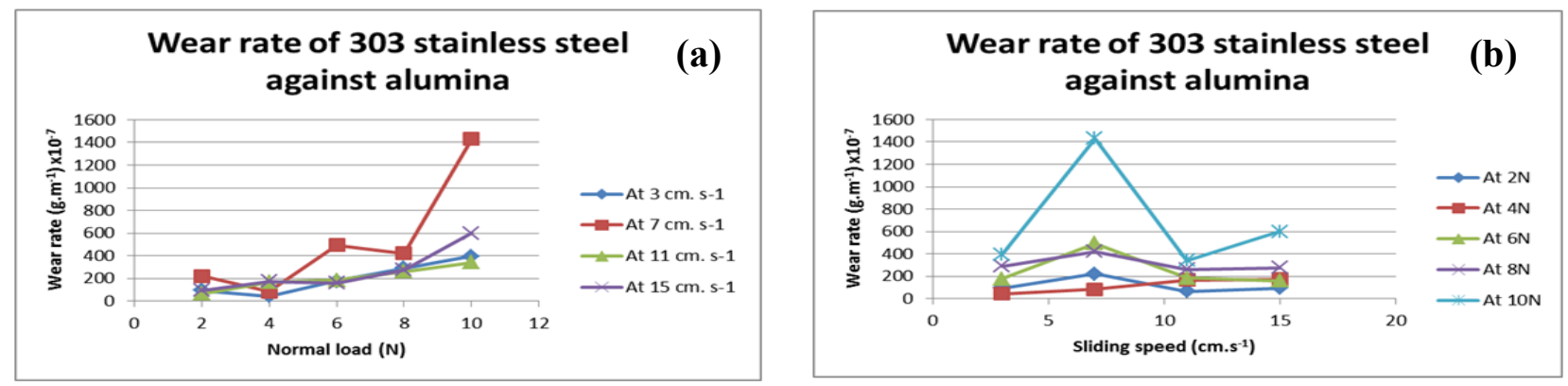

Fig. 5. a) Wear rate vs normal load, b) Wear rate vs sliding speed of 303stainless steel against alumina

\subsection{TiC coated $303 \mathrm{SS}$ against alumina counterface}
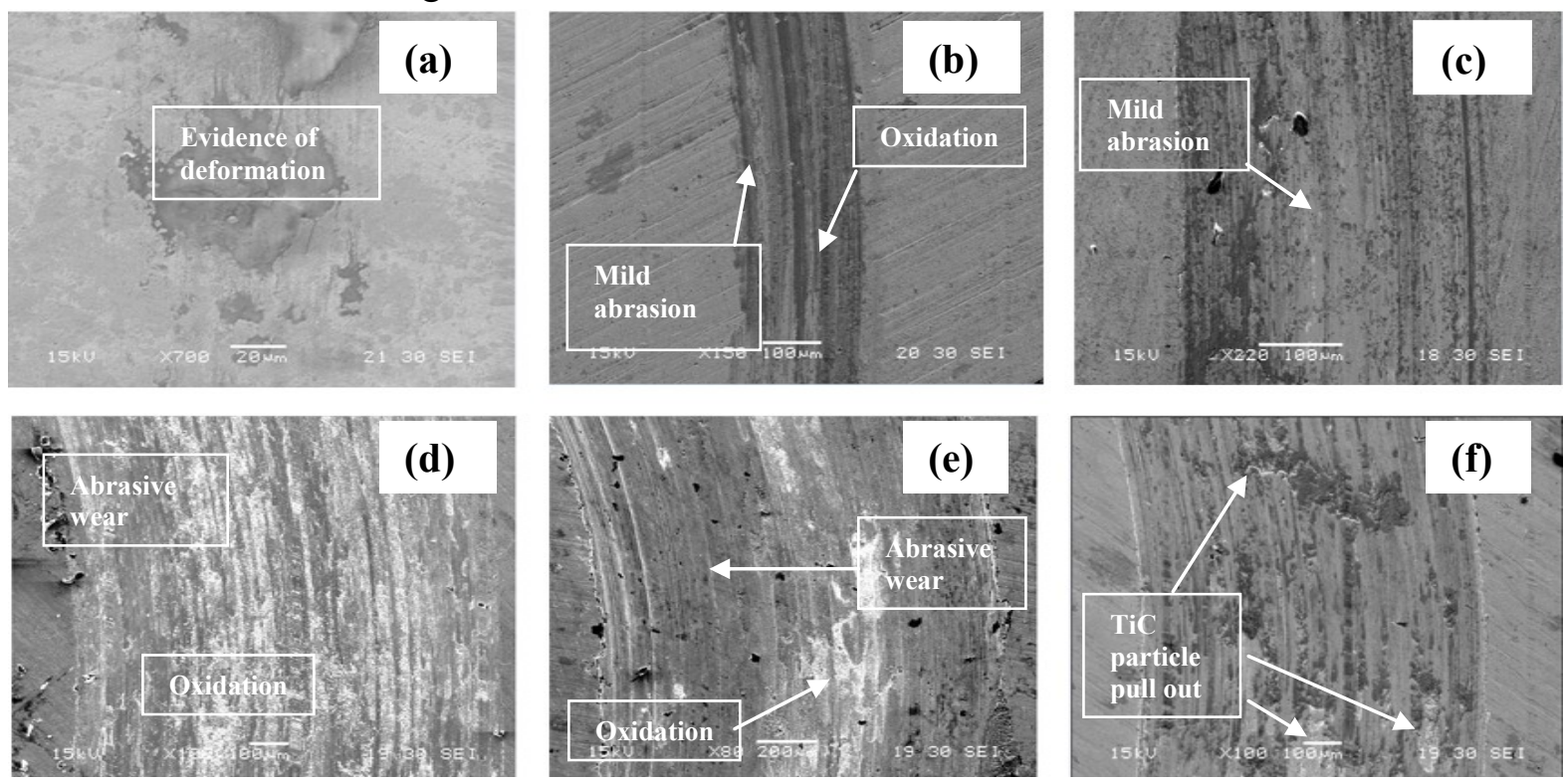
Fig. 6. SEM micrograph of the wear tracks, a) $2 \mathrm{~N}$ normal load and $3 \mathrm{~cm} \cdot \mathrm{s}^{-1}$ sliding speed, b) $8 \mathrm{~N}$ normal load and $3 \mathrm{~cm} \cdot \mathrm{s}^{-1}$ sliding speed, c) $10 \mathrm{~N}$ normal load and $7 \mathrm{~cm} \cdot \mathrm{s}^{-1}$ sliding speed, d) $6 \mathrm{~N}$ normal load and $15 \mathrm{~cm} \cdot \mathrm{s}^{-1}$ sliding speed, e) $8 \mathrm{~N}$ normal load and $11 \mathrm{~cm} . \mathrm{s}^{-1}$ sliding speed and f) $8 \mathrm{~N}$ normal load, and $7 \mathrm{~cm} . \mathrm{s}^{-1}$ sliding speed
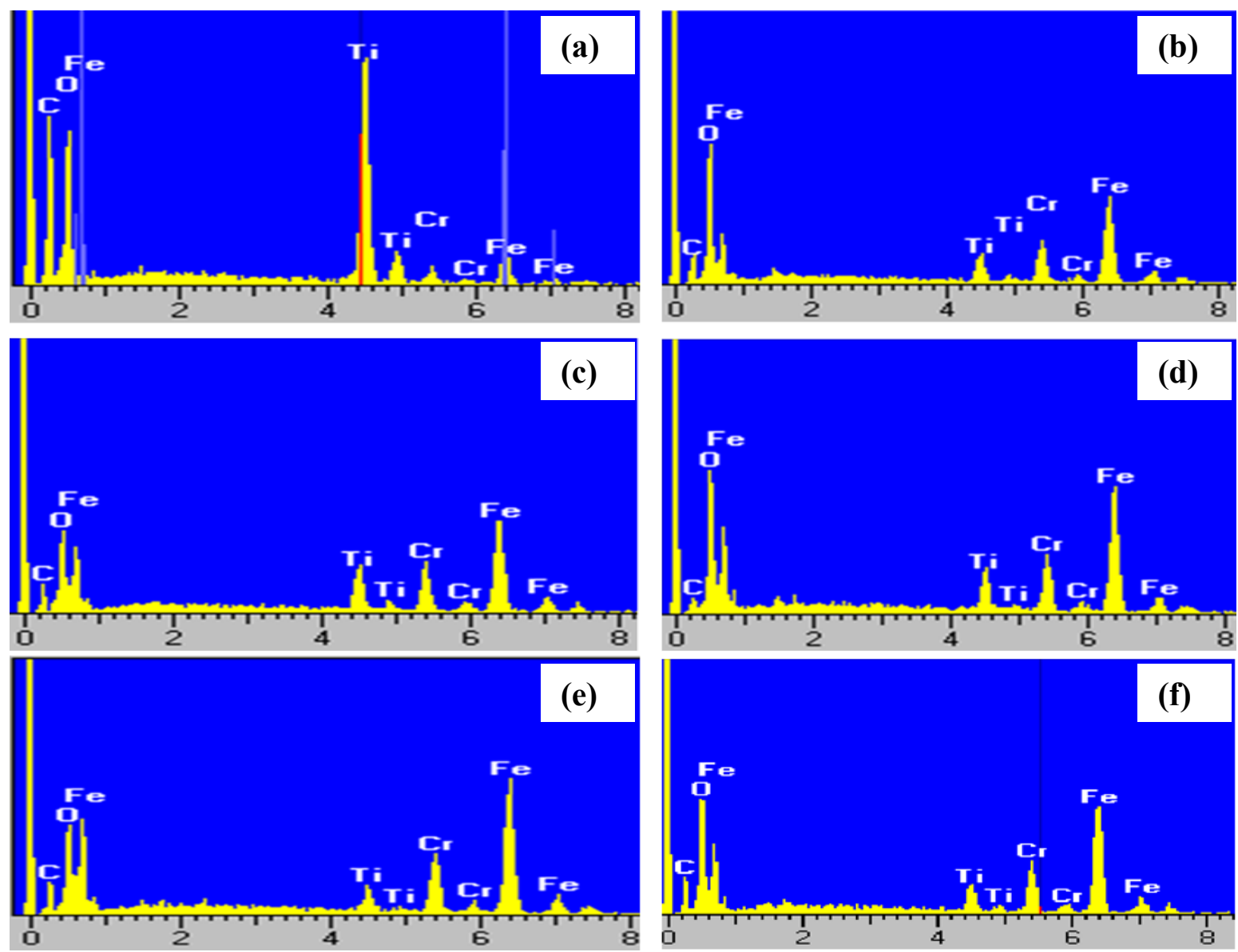

Fig. 7. EDX analysis of the wear tracks, a) $2 \mathrm{~N}$ normal load and $3 \mathrm{~cm} . \mathrm{s}^{-1}$ sliding speed, b) $8 \mathrm{~N}$ normal load and $3 \mathrm{~cm} . \mathrm{s}^{-1}$ sliding speed, c) $10 \mathrm{~N}$ normal load and $7 \mathrm{~cm} \cdot \mathrm{s}^{-1}$ sliding speed, d) $6 \mathrm{~N}$ normal load and $15 \mathrm{~cm} . \mathrm{s}^{-1}$ sliding speed, e) $8 \mathrm{~N}$ normal load and $11 \mathrm{~cm} \cdot \mathrm{s}^{-1}$ sliding speed, and f) $8 \mathrm{~N}$ normal load and $7 \mathrm{~cm} . \mathrm{s}^{-1}$ sliding speed

Table 5. Wear rate of TiC against alumina at constant sliding speeds and various normal loads

\begin{tabular}{|l|l|l|l|l|}
\hline Normal load $(\mathrm{N})$ & $\begin{array}{l}\text { Wear rate }\left(\mathrm{g} \cdot \mathrm{m}^{-1}\right) \\
\mathrm{x} 10^{-7} \text { at } 3 \mathrm{~cm} \cdot \mathrm{s}^{-1}\end{array}$ & $\begin{array}{l}\text { Wear rate }\left(\mathrm{g} \cdot \mathrm{m}^{-1}\right) \\
\mathrm{x} 10^{-7} \text { at } 7 \mathrm{~cm} \cdot \mathrm{s}^{-1}\end{array}$ & $\begin{array}{l}\text { Wear rate }\left(\mathrm{g} \cdot \mathrm{m}^{-1}\right) \\
\mathrm{x} 10^{-7} \text { at } 11 \mathrm{~cm} \cdot \mathrm{s}^{-1}\end{array}$ & $\begin{array}{l}\text { Wear rate }\left(\mathrm{g} \cdot \mathrm{m}^{-1}\right) \\
\mathrm{x} 10^{-7} \text { at } 15 \mathrm{~cm} \cdot \mathrm{s}^{-1}\end{array}$ \\
\hline 2 & 2 & 2 & 45 & 78 \\
\hline 4 & 17 & 2 & 32 & 68 \\
\hline 6 & 6 & 4 & 47 & 76 \\
\hline 8 & 6 & 96 & 132 \\
\hline 10 & 22 & 96 & 110 \\
\hline
\end{tabular}

Table 6. Wear rate of TiC coating against alumina at constant normal loads and various sliding speeds

\begin{tabular}{|l|l|l|l|l|l|}
\hline $\begin{array}{l}\text { Sliding speed } \\
\left(\mathrm{cm} \cdot \mathrm{s}^{-1}\right)\end{array}$ & $\begin{array}{l}\text { Wear rate } \\
\left(\mathrm{g} \cdot \mathrm{m}^{-1}\right) \times 10^{-7} \\
\text { at } 2 \mathrm{~N}\end{array}$ & $\begin{array}{l}\text { Wear rate } \\
\left(\mathrm{g} \cdot \mathrm{m}^{-1}\right) \times 10^{-7} \\
\text { at 4N }\end{array}$ & $\begin{array}{l}\text { Wear rate } \\
\left(\mathrm{g} \cdot \mathrm{m}^{-1}\right) \times 10^{-7} \\
\text { at } 6 \mathrm{~N}\end{array}$ & $\begin{array}{l}\text { Wear rate } \\
\left(\mathrm{g} \cdot \mathrm{m}^{-1}\right) \times 10^{-7} \\
\text { at } 8 \mathrm{~N}\end{array}$ & $\begin{array}{l}\text { Wear rate } \\
\left(\mathrm{g} \cdot \mathrm{m}^{-1}\right) \times 10^{-7} \\
\text { at } 10 \mathrm{~N}\end{array}$ \\
\hline 3 & 2 & 17 & 6 & 6 & 8.5 \\
\hline
\end{tabular}




\begin{tabular}{|l|l|l|l|l|l|}
\hline 7 & 2 & 2 & 4 & 22 & 20 \\
\hline 11 & 45 & 32 & 47 & 96 & 96 \\
\hline 15 & 78 & 68 & 76 & 132 & 110 \\
\hline
\end{tabular}
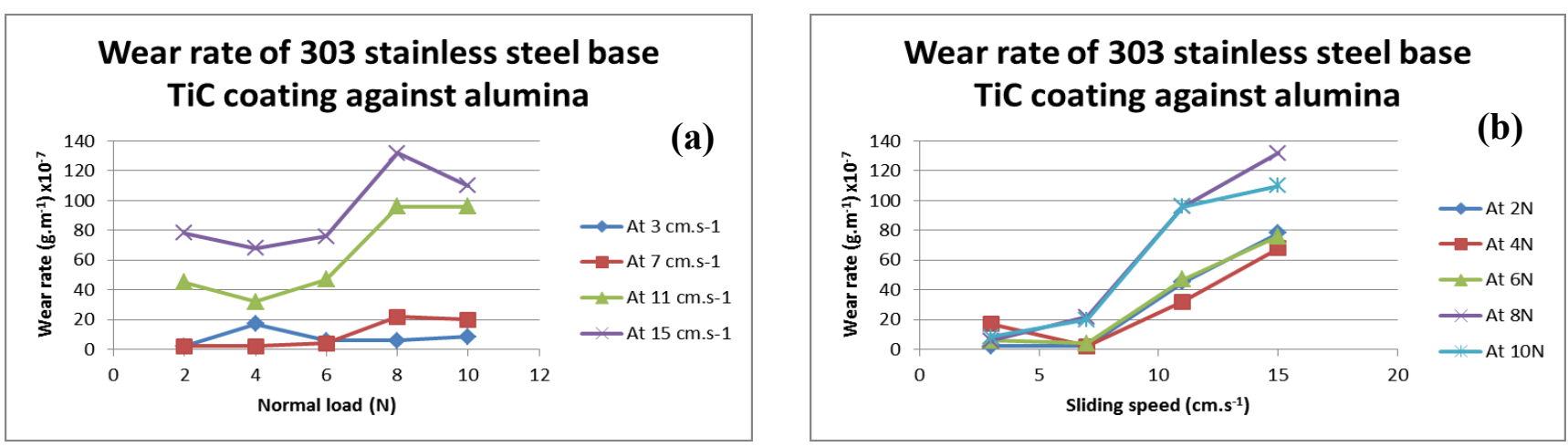

Fig. 8. a) Wear rate vs normal load, b) Wear rate vs sliding speed of TiC against alumina

3.3. Wear trend and coefficient of friction comparison of 303SS and TiC coating against alumina
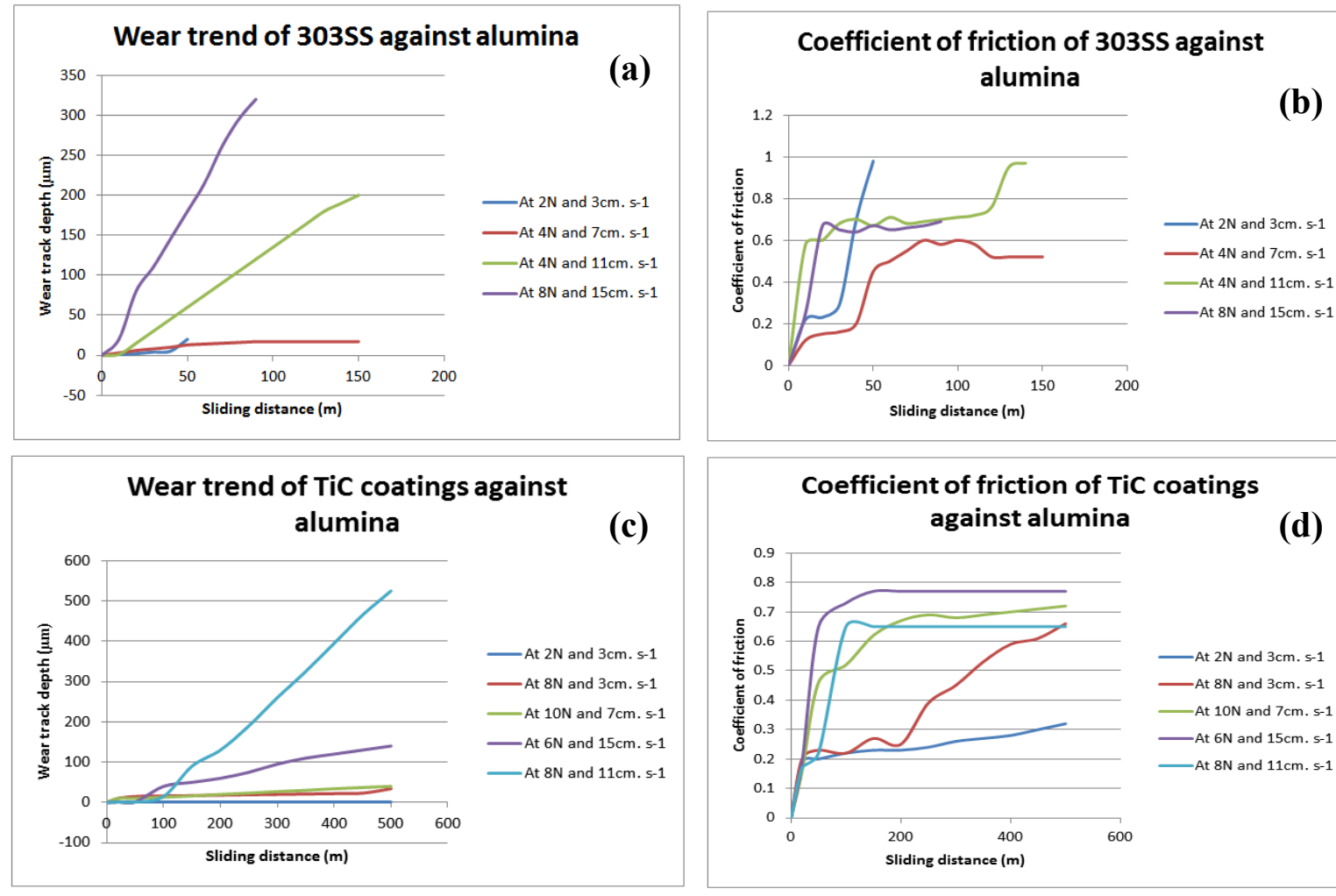

Coefficient of friction of 303SS against alumina
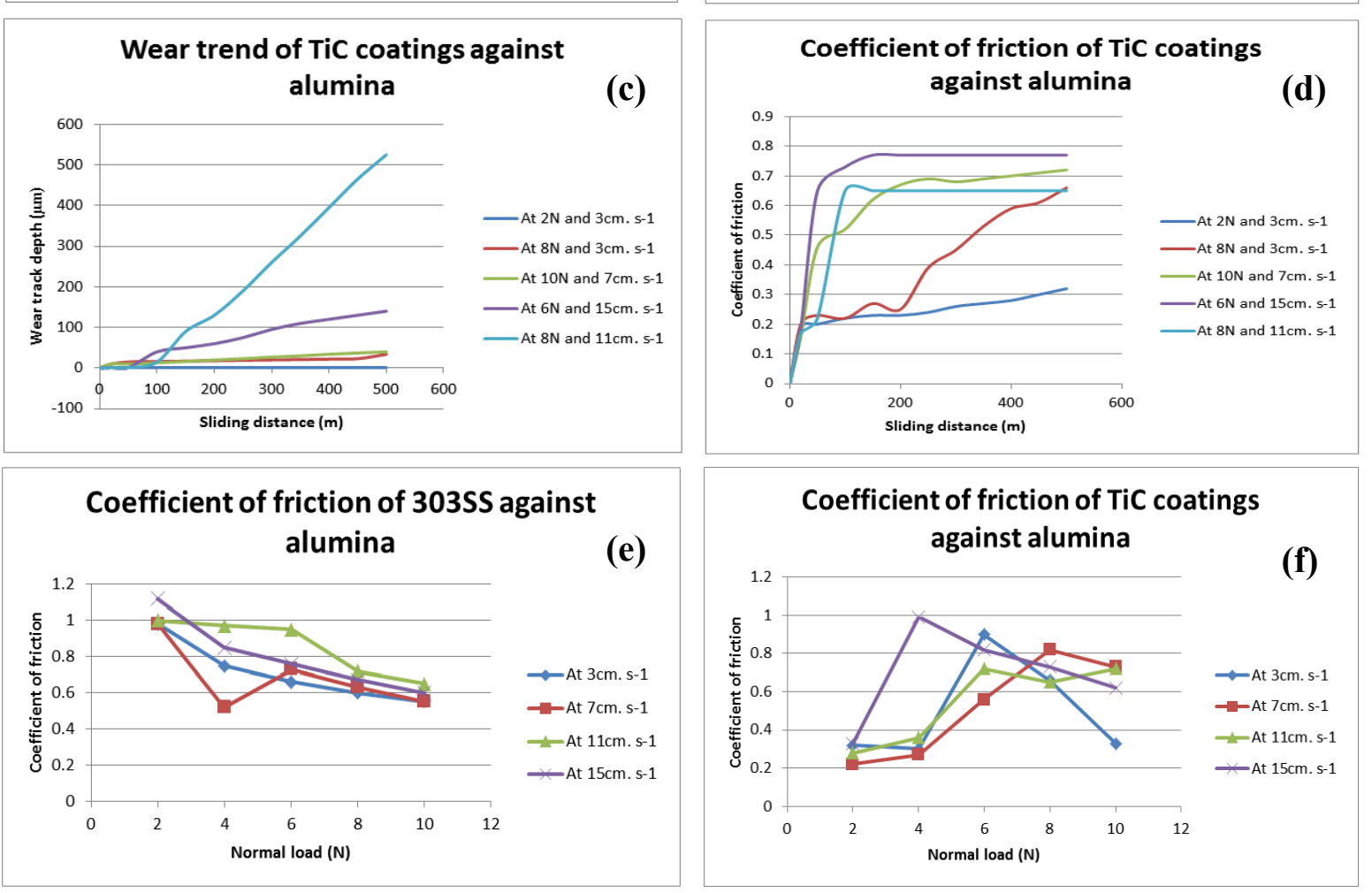
Fig. 9. Wear rate trends and coefficient of friction comparison of 303 stainless steel and TiC coatings against alumina, a) wear of $303 \mathrm{SS}$ against alumina, b) coefficient of friction of $303 \mathrm{SS}$ against alumina, c) wear of $\mathrm{TiC}$ coatings against alumina, d) coefficient of friction of $\mathrm{TiC}$ coatings against alumina, e) coefficient of friction of 303SS against alumina for the range of normal loads and sliding speeds and f) ) coefficient of friction of TiC coatings against alumina for the range of normal loads and sliding speeds

3.4. Wear rate comparison of $303 \mathrm{SS}$ and $\mathrm{TiC}$ coating against alumina
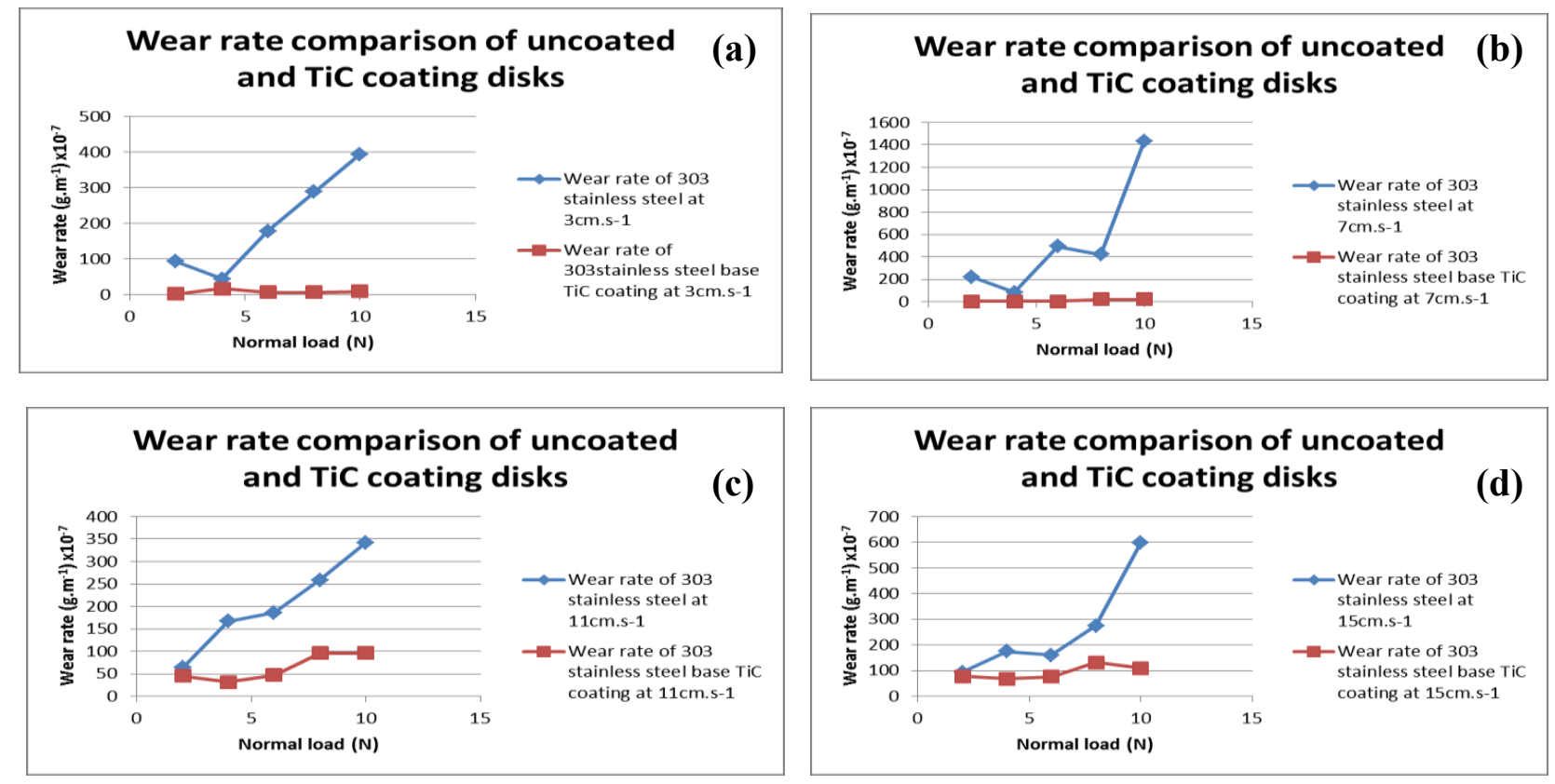

Fig. 10. Wear rate comparison of 303 stainless steel and TiC coatings, a) at $3 \mathrm{cms}^{-1}$ sliding speed and various normal load, b) at $7 \mathrm{cms}^{-1}$ sliding speed and various normal load, c) at $11 \mathrm{cms}^{-1}$ sliding speed and various normal load and d) at $15 \mathrm{cms}^{-1}$ sliding speed and various normal load

\subsection{Total mass loss comparison}

For each tests, new disks were used for a combination of sliding speed and normal load for $500 \mathrm{~m}$ sliding distance. Five tests were carried out for each constant speed at variable loads from 2 to $10 \mathrm{~N}$, and increasing in $2 \mathrm{~N}$ increments. The following table shows the total mass loss of the 303 stainless steel and TiC coating disks against alumina ball at each constant speed for the range of normal load.

Table 7.The total mass loss of 303 stainless steel and TiC coating against alumina at different speeds and normal loads

\begin{tabular}{|l|l|l|}
\hline $\begin{array}{l}\text { Sliding speed } \\
\left(\mathrm{cm} \cdot \mathrm{s}^{-1}\right)\end{array}$ & $\begin{array}{l}\text { Total mass loss }(\mathrm{g}) \text { of 303stainless } \\
\text { steel uncoated disks }\end{array}$ & $\begin{array}{l}\text { Total mass loss }(\mathrm{g}) \text { of 303stainless steel base } \\
\text { TiC coating disks }\end{array}$ \\
\hline 3 & 0.05 & 0.002 \\
\hline
\end{tabular}




\begin{tabular}{|l|l|l|}
\hline 7 & 0.132 & 0.003 \\
\hline 11 & 0.051 & 0.016 \\
\hline 15 & 0.065 & 0.023 \\
\hline
\end{tabular}

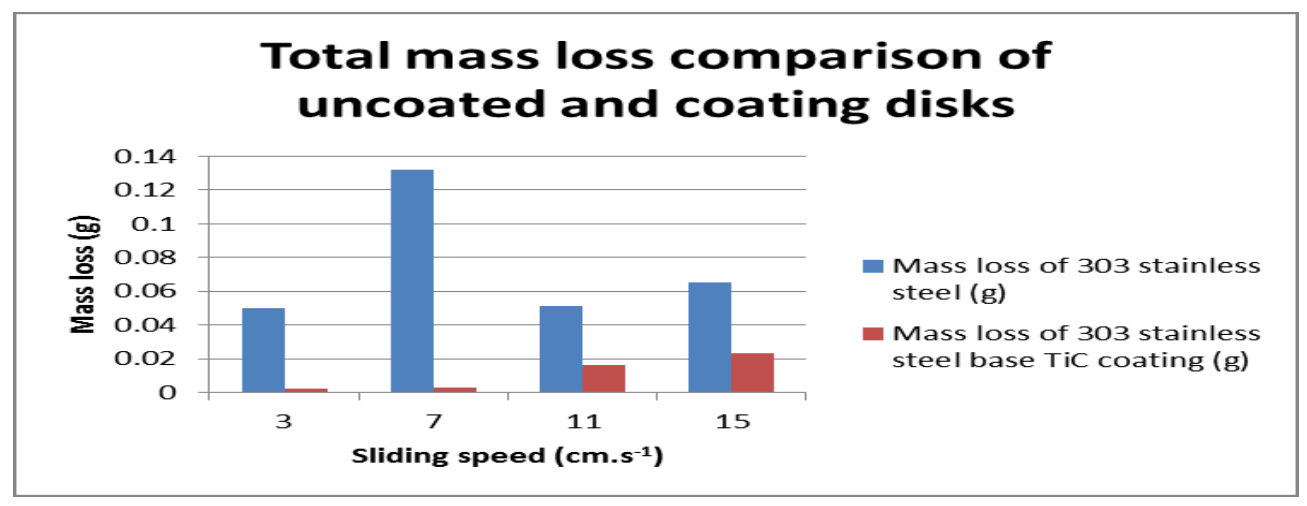

Fig. 11. Total mass loss comparison of 303 stainless steel and303 stainless steel base TiC coating at each constant speed for the range of normal loads

\subsection{Optical micrograph}
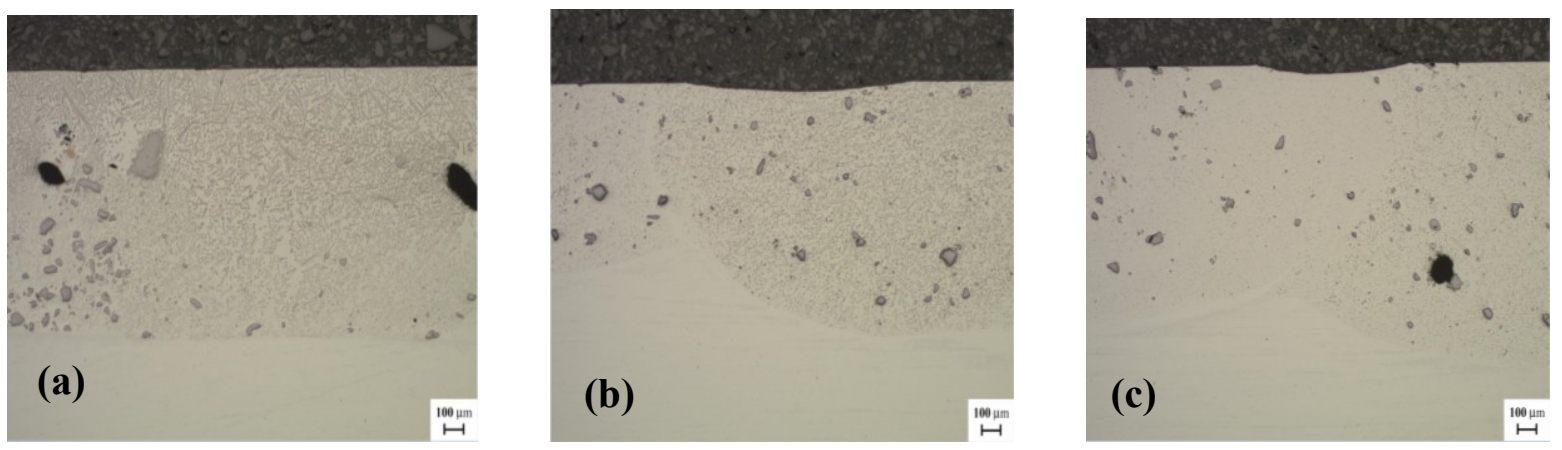

Fig. 12. Optical micrograph of wear tracks of $\mathrm{TiC}$ coating against alumina, a) $7 \mathrm{~cm} \cdot \mathrm{s}^{-1}$ sliding speed and $10 \mathrm{~N}$ normal load, b) $11 \mathrm{~cm} \cdot \mathrm{s}^{-1}$ sliding speed and $10 \mathrm{~N}$ normal load and c) $15 \mathrm{~cm} \cdot \mathrm{s}^{-1}$ sliding speed and $10 \mathrm{~N}$ normal load

3.6. Wear behaviour of uncoated 303 stainless steel and 303 stainless steel base TiC composite coating against alumina ball

For the uncoated 303 stainless steel, generally for the range of sliding speeds and normal load considered, higher wear was found i.e. the wear surfaces showed evidence of plastic deformation and abrasion with delamination evident on the wear tracks, Fig. 3, and Tables 34. Conditions of mild wear observed were consistent with plastic deformation [24] and oxidation of wear track, Fig. 3(b), as has been observed in other work on these materials [31]. It was interesting that there were observed peaks in the wear rate with increases in applied load and sliding speed, indicative of transitions in wear regimes, Figs. 5(a-b) \& 9(a). EDX analysis Figs. 4(b-c), indicated traces of oxidation on the surfaces, suggesting that oxidation was influencing the wear in these conditions. The coefficient of friction fluctuated 
significantly for all combination of sliding speeds and normal loads during the course of tests Fig. 9(b).

On the contrary for the TiC composite coatings, at lower sliding speeds and normal loads there was significantly less degradation on the surfaces, with only minor evidence of deformation and oxidation of the wear tracks Figs. 6(a-c). At higher loads, Figs. 6(d-f), Tables 5-6, there was evidence of oxidation on the surface and this was confirmed by EDX analysis and by the variation of the coefficient of friction Fig. 9(d). The effects of increase load on the mass loss and sliding speed trends indicated transitions in regimes, Fig. 8(a-b), with the wear rates peaking at intermediate loads. A comparison between the mass loss data for the coated and uncoated steel indicated little difference at low loads, but change in mechanism as the load increased, with a sharp rise in wear rate for the uncoated material Fig. 11 .

Optical microscopy of the surfaces, Fig. 12 shows the stages in deformation of the coating surface with increments in sliding speed, with significant deformation at higher speeds.

\section{Discussion}

4.1 Wear mechanisms for coated and uncoated steel

During the dry sliding wear tests of 303 stainless steel against alumina, the results indicate that no test completes its total sliding distance i.e. 500m Fig. 9(a \& b). This occurs because of the significantly higher hardness of alumina compared to 303 stainless steel, consistent with other results in the literature [14]. The 303 stainless steel exhibits very poor wear resistance against alumina during dry sliding wear under ambient conditions, resulting in relatively higher wear rates for the range of sliding speed and normal load tested. Similar phenomena are observed during the study of dry sliding wear behaviour of group of composite materials based on alumina short fibre reinforced Al-SI alloy against steel. The abrupt increase in wear rate occurs when un-reinforced Al-SI is tested against steel [15].

The 303stainless steel disk undergoes several wear transitions. At low sliding speeds, material transfer from the steel disk to the alumina ball occurs and this transferred material is oxidized and forms a layer on the contact surface of the alumina counterface. Subsequently, further sliding occurs between oxidized matrial of coating and steel substrate, in areas of contact on the wear track [23].

On the other hand during the dry sliding wear tests of the TiC coating against alumina, almost all tests completed their test sliding distance Fig. 9(c \& d). Due to the presence of the TiC coating, the relative surface hardness of the substrate increases, thereby enhancing the sliding wear resistance of the substrate significantly [16]. This result in a substantial decrease in wear rate of the substrate against alumina. 
The wear rate of the TiC coating is observed to be very low compared to the uncoated material Table $3 \& 5$ and Fig. 5a \& 8a. Hence, the TiC coating improves the wear resistance of the substrate significantly [17]. This results in an additional wear regime i.e. very mild wear at the low speed. EDX analysis of the wear tracks Fig. 7(a) to 7(e) and the micrographs of the wear tracks Fig.12 indicate that there is evidence of TiC coating on the worn surface after the tests. This suggest that the coating exhibits favourable resistance to the tribooxidative conditions.

The total mass loss comparison between 303 stainless steel and the TiC coating against alumina ball show a significant increase in wear resistance due to coating Fig. 11, [6]. The dry sliding wear test results show that the relative wear resistance of the TiC composite coating produced by the TIG melt method is significantly higher than that of substrate Fig. 10. This reveals that wear rate, wear modes and wear mechanisms of uncoated and coated materials differ significantly. Similar findings are obtained in the case of wear of TiC-coated carbide tools in dry turning for flank and crater [19].

The increase in wear rate of TiC coating against alumina Fig. $8(\mathrm{a} \& \mathrm{~b})$ is also found in other studies i.e. for TiN coating against high speed steel at $0.7 \mathrm{~m} \cdot \mathrm{s}^{-1}$ [20], PVD-TiAlN coated carbide [27], plasma sprayed TiC-NiCrBSi coatings [34], under dry sliding wear behaviour of TIG welding clad WC composite coatings [35], friction and wear behaviour of tungsten and titanium carbide coatings [6] and for other titanium based coatings [36].

It is interesting that the alumina ball mated with 303 stainless steel and 303 stainless steel base TiC coated disks exibits a substantial amount of one-way transfer of material from disk to ball. This material transfer results in a smoothening of counterface. As a result of metal on metal oxide transfer, adhesion between ball and disk is enhanced and back transfer, mutual transfer and finally production of a so-called "mechanically mixed layer" occurs[14]. This mode of material transfer is also observed in the case of HSS base TiN-coated disk against HSS pin [26].

As stated above, the coefficient of friction for both uncoated and coated 303SS uncoated and coated, Fig. 9(e \& f) fluctuates considerably with increase in sliding speed and normal load. $\mathrm{Up}$ to $4 \mathrm{~N}$, the coefficient of friction of the $\mathrm{TiC}$ is approximately $60 \%$ lower than that of the uncoated 303SS against alumina for all sliding speeds. The higher value of the coefficient of friction of the uncoated 303SS is possibly due to plastic deformation and abrasive wear arising from contact with the harder counterpart Fig 3(a), whereas that observed for $\mathrm{TiC}$, at higher loads at all sliding speeds Fig. 9(f), may be due to abrasive wear that results in pullout of TiC particles, Fig. 6(f).

The results above indicate several transitions in the wear rate versus load and sliding velocity. This behaviour is also noted by Hirst and Lancaster in brass [28] and by Saka et al. [29] in steel and is attributed to a competition between strain hardening and thermal softening that may occur simultaneously at the surface of the material as the sliding speed increases [24]. Similarly, it can be postulated that in this case, following transfer of material to the alumina 
ball, the strain hardening effect dominates initially, firstly reducing the wear, but this is counterbalanced by the softening of surface layers as a result of frictional heating and the effects of oxidation.

\subsection{Wear regimes and maps}

Wear maps can represent the mechanistic changes on the worn material and the counterface over a range of operating conditions [19]. Wear mode maps identify the mode of degradation and establish the level of wastage rate and potential "safe" and "unsafe" operation conditions for materials [21]. On the other hand, wear mechanistic maps show the different wear mechanism for various combination of sliding speed and normal load for different materials sliding against each other under dry sliding conditions (in this case) on the basis of wear rate, surface damage and wear mechanism information [22]. Such maps link the observed wear mechanisms to the actual conditions. These maps demonstrate clearly that transitions from one dominant wear mechanism to another may also be identified by changes in measured wear rates [19].

Wear mechanism maps approaches have been adopted for a wide variety of material combinations including steel-on-steel [32], steel against nitride steel [23], ceramic wear [23], aluminium alloys [24], aluminium metal matrix composites [25] and TiN-coated high speed steel [26]. The wear mode regimes are classified on the basis of wear rates Table $3 \& 5$ and then these are correlated with wear mechanistic regimes. A tribo-system approach has been adopted to study the wear behaviour 303 stainless steel and TiC coating against alumina:

a-1) Very mild wear $<20 \times 10^{-7}\left(\right.$ g.m $\left.{ }^{-1}\right)$

a) $20 \times 10^{-7}\left(\right.$ g.m $\left.\mathrm{m}^{-1}\right)=$ mild wear $\leq 91 \times 10^{-7}\left(\mathrm{~g} \cdot \mathrm{m}^{-1}\right)$

b) $91 \times 10^{-7}\left(\right.$ g.m $\left.\mathrm{m}^{-1}\right)<$ medium wear $\leq 274 \times 10^{-7}\left(\right.$ g.m $\left.\mathrm{m}^{-1}\right)$

c) Severe wear $>274 \times 10^{-7}\left(\mathrm{~g} \cdot \mathrm{m}^{-1}\right)$

\subsubsection{Wear mode maps}
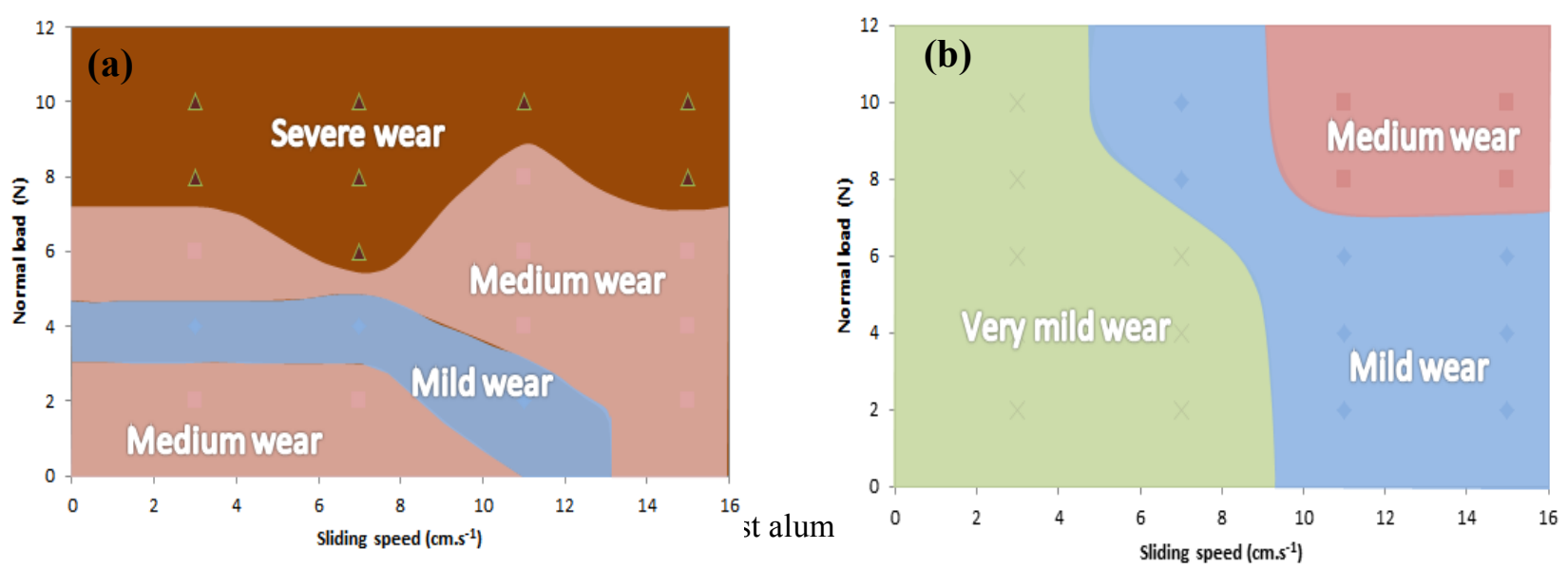
As shown on Fig. 13(a), the wear mode map of 303stainless steel against alumina shows that the severe wear predominates at all speeds and at relatively high loads. For the TiC coating sliding against alumina Fig. 13(b), mild wear is more dominant for the range of sliding speeds and normal loads. It is clear that due to the presence of the coating, the mild wear regime is expanded to a higher range of sliding speeds and normal load with an additional wear mode i.e. very mild wear and with an elimination of the severe wear. Moreover in Fig. 13(a-b), the combination of the very mild and mild wear zone can be regarded as the safe operation zone for the coated and uncoated steels against alumina respectively [19].

\subsubsection{Wear mechanism maps}

Wear mechanism maps are useful tools for analysing the change in regime over a multiparameter space.

The regimes below are based on the experimental observations above.

These can be summarized as:

- Adhesive wear

- Adhesive-oxidative wear

- Oxidative- adhesive wear

- Oxidative-abrasive wear

The maps for the coated and uncoated steel exhibit significant transitions with similar regimes in the low load -sliding speed window but abrasive wear dominating the maps for steel at higher loads and sliding speeds, Fig. 14(a), with oxidative and deformation mechanisms dominating the wear mode at intermediate loads and high sliding speeds.
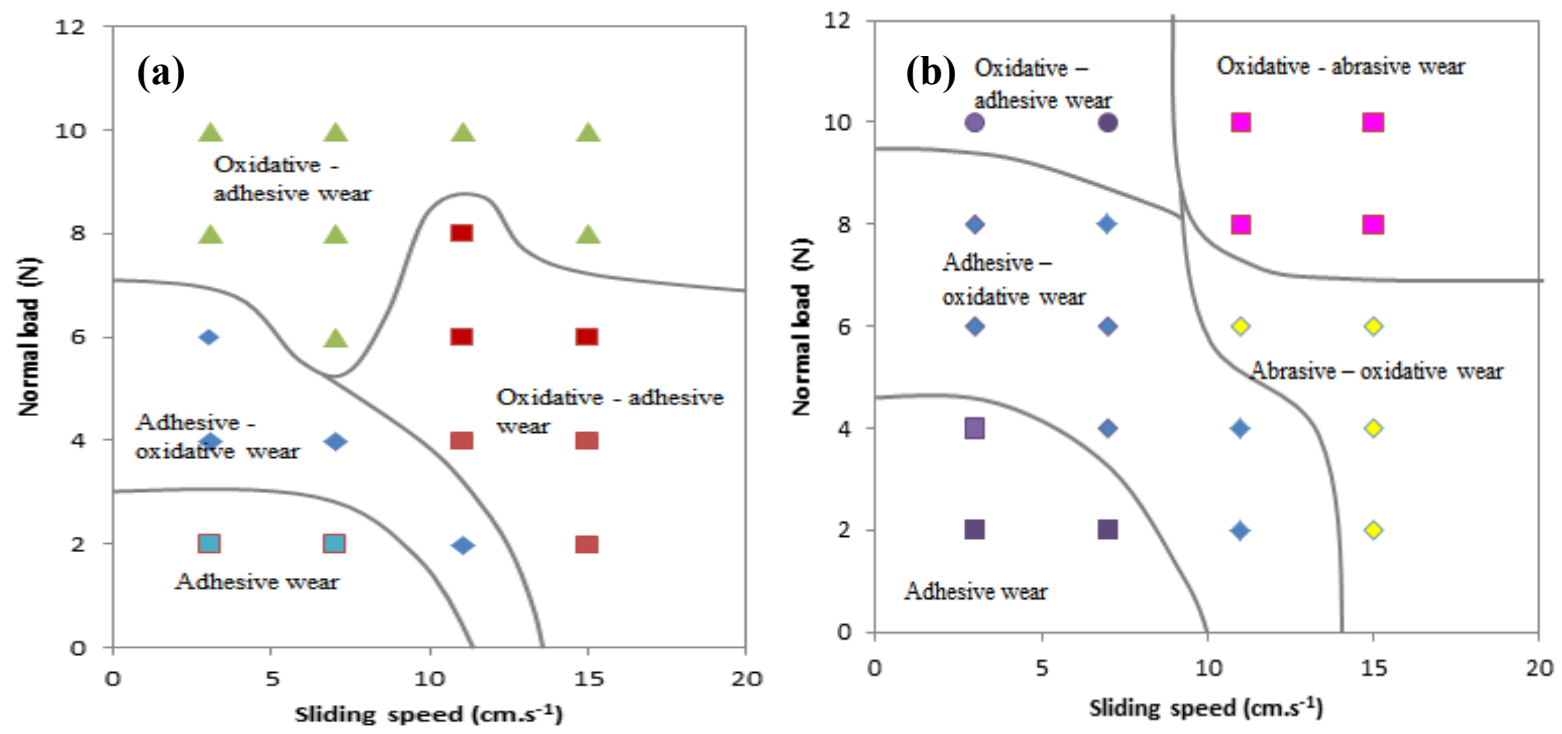
Fig. 14. The wear mechanism map, a) 303 stainless steel against alumina and b) TiC coating against alumina

4.2.3. Wear mechanisms and regimes for 303 stainless steel base TiC coatings

For the TiC coatings, the wear regimes suggested are as follows, and again are based on the experimental and microscopic observations above.

- Adhesive wear

- Adhesive-oxidative wear

- Oxidative-adhesive wear

- Oxidative-abrasive wear

- Abrasion-oxidative wear

The results, Fig. 14(a-b), indicate very different wear map configurations for both materials, with ploughing and oxidation dominating the wear map at high loads and speeds, and very little evidence of abrasive wear for the coating, which indicate that in this window of conditions, the coating provides resistance to the environment. In particular, abrasion dominates the upper part of the map for the steel, with some oxidation affected areas apparent, whereas for the more wear resistant coating, this window of conditions is characterized by oxidative wear mechanisms. Clearly, the transitions between the regimes are identified through SEM analysis of surface morphologies and therefore are a relatively arbitrary method of defining regime transitions; however, the extent of oxidation and thus oxidative wear are much higher for the steel, Fig. 14(a) compared to the coating, Fig. 14(b), at lower loads. The various transitions at intermediate loads and velocities can be attributed to the competition between oxidation, wear resistance, and extent of frictional heating between both surface and counterface materials.

4.3. Comparison between wear mechanism maps for 303 stainless steel sliding against low alloy steel counterface

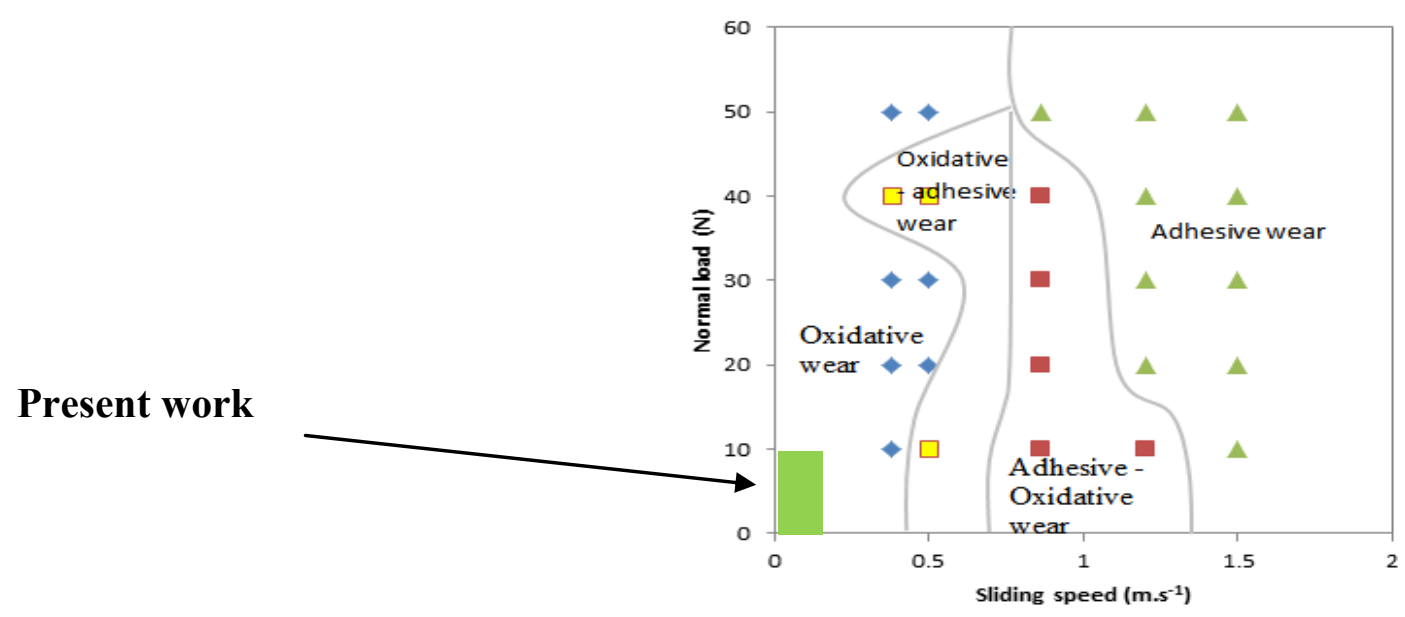

Fig. 15. Wear mechanism map for 303stainless steel disk against 8620 low alloy steel 
Fig. 15 shows the range of sliding speed and normal load involved in the present study, which can be compared with previous work by the current authors. It is clear from this figure that the wear mechanism of the 303 stainless steel against 8620 low alloy steel is dominated by oxidative wear; while from Fig. 14(a) above, against an alumina counterface, a very different mode is observed i.e. abrasive dominated, and this is possibly due to lower frictional heating in the latter case.

Clearly, the wear maps developed above indicate many possible wear regime transitions between coated and uncoated materials and using different counterface materials. Further work will be to investigate the wear mechanisms of coatings of varying such as volume fraction and size to provide a basis for coating optimization in such conditions.

\section{Conclusions}

- A series of sliding wear tests have been carried out for TiC coated and uncoated 303 stainless steel sliding against alumina counterface. The results indicate that the uncoated steel exhibited poor wear resistance, while the TiC coating increased the wear resistance of the substrate considerably, in this window of conditions.

- Significant differences in wear regimes were identified for both materials, with more evidence of oxidation for the coated material in these conditions and abrasion dominating the wear mechanisms for the steel, in particular at higher loads and sliding speeds. In each case, oxidative wear was observed to influence the wear mechanisms at intermediate loads and speeds.

- Wear maps have been constructed based on the results, indicating many possible wear regimes for both materials, and significant differences in material loss mechanisms for the TiC coating by comparison with the $303 \mathrm{SS}$.

\section{Acknowledgements}

We would like to thank (IIUM, Malaysis) for providing the test specimens and facilities for the present work and in particular Dr Shahjahan Mridha, Leverhulme Trust Visiting Professor -grant RL7583- to the University of Strathclyde, 2012-2013, for collaboration on this project.

\section{References}

[1] Y. F. Liu, J. S. Mu, X. Y. XU, S. Z. Yang, Microstructure and dry-wear properties of TiC- reinforced composite coating prepared by plasma-transferred arc weld-surfacing process, Materials Science and Engineering A 458 (2007), Pages 366-370

[2] A. Devaraju, A. Elaya Perumal, J. Alphonsa, Satish V. Kailas, S. Venugopal, Sliding wear behaviour of plasma nitride Austenitic Stainless Steel Type AISI 316LN in 
temperature range from 25 to 400 centigrade at $10^{\wedge}-4$ bar, Wear, 288(2012), Pages 17-26.

[3] Shiv Kumar, Ashish Bhattacharyya, Dipak Kumar Mondal, Koushik Biswas, Joydeep Maity, Dry sliding wear behaviour of medium carbon steel against alumina disk, Wear, 270 (2011), Pages 413-421.

[4] Y. C. Lin, S. W. Wang, T. M. Chen, A study on the wear behaviour of hardened medium carbon steel, Journal of Materials Processing Technology, 120 (2002), Pages 126-132.

[5] Y. Guilmard, J. Denape and J. A. Petit, Friction and wear thresholds of alumenachromium steel pairs sliding at high speeds under dry and wet conditions, Tribology International, 26 (1993), Pages 29-39.

[6] S. Bahadur, Chien-Nan Yang, Friction and wear behaviour of tungsten and titanium carbide coatings, Wear, 196 (1996), Pages 156-163.

[7] H. E. Hintermaan, Adhesion, friction and wear of thin hard coatings, Wear, 100 (1984), Pages 381-397.

[8] P. Wallen and S. Hogmark, Influence of TiN coating on wear of high steel at elevated temperature, Wear, 130 (1989), Pages 123-135.

[9] J. L. Olivares and L. C. Grigorescu, Friction and wear behaviour of thermally sprayed nichrome-WC coatings, Surface and Coating Technology, 33 (1987), Pages 183-190.

[10] S. J. Bull, D. S. Rickertson and A. Hendry, The abrasive wear resistance of sputter ion plated titanium nitride coatings, Surface and Coatings Technology, 36 (1988), Pages 743-754.

[11] D. S. Rickerby and P. J. Burnett, The wear and erosion resistance of hard PVD coatings, Surface and coatings Technology, 33 (1987), Pages 191-211.

[12] H. Kitsunai, N. Tsumaki and K. Kato, Transitions of microwear mechanism for Cr2O3 ceramic coatings during repeated sliding observed in an SEM.tribosystem, in K. C. Ludema and R. G. Bayer (eds.), Wear of materials, ASME, New York, 1991, Pages 249-255.

[13] S. Mridha, A. N. Md. Idriss, TN Baker, 2012, From: Introduction to physical metallurgy of welding, K.E. Easterling 1992 and Incorporation of TiC particulates on AISI 4340 low alloy steel surface via TIG arc melting.

[14] K. H. ZUM GAHR, Sliding wear of ceramic- ceramic, ceramic-steel and steel-steel pairs in lubricated and unlubricated contact Wear, 133 (1989), Pages 1-22.

[15] J.-Q. Jiang, R.-S. Tan, Dry sliding wear of an alumina short fibre reinforced Al-S1 alloy 
Against Steel, Wear, 195 (1996), Pages 106-111.

[16] K. H. Habig, Wear behaviour of surface coatings on steels, Tribology International, 22 (1989), Pages 65-73.

[17] T.S. Eyre, D. Maynard, Surface aspects of unlubricated metal-metal wear, Wear, 18 (1971), Pages 301-310.

[18] R. Lalitha, Katipelli, Arvind Agarwal, Narendra, B. Dahotre, Laser Surface engineered TiC coating on 6061 Al alloy: microstructure and wear, applied, Surface Science, 153 (2000), Pages 65-78.

[19] C. Y. H. Lim, S. C. Lim, K. S. Lee, Wear of TiC-coated carbide tools in dry turning, Wear, 225-229 (1999), Pages 354-367.

[20] S. Wilson, A. T. Alpas, TiN coating wear mechanisms in dry sliding contact against high speed steel, Surface Coatings Technology, 108-109 (1998), Pages 369-376.

[21] M. M. Stack, W. Huang, G. Wang, C. Hodge, Some views on the construction of bio-tribo-corrosion maps for Titanium alloys in Hank's solution: Particle concentration and applied loads effects, Tribology International, 44 ( 2011), Pages1827-1837.

[22] M. M. Stack, Mapping tribo-corrosion processes in dry and in aqueous conditions: some new directions for the new millennium, Tribology International, 35 (2002), Pages 681-689.

[23] P. Gautier and K. Kato, Wear mechanism of silicon nitride, partially stabilized zirconia and alumina in unlubricated sliding against steel, Wear, 162-164 (1993), Pages 305-313.

[24] J. Zhang and A. T. Alpas, Transition between mild and severe wear in aluminium alloys, Acta Mater., 45 (1997), Pages 513-528.

[25] S. Wilson, A. T. Alpas, Wear mechanism maps for metal matrix composites, Wear, 212 (1997), Pages 41-49.

[26] S. Wilson, A. T. Alpas, Wear mechanism maps for TiN-coated high speed steel, Surface and Coatings Technology, 120-121 (1999), Pages 519-527.

[27] W. Grzesik, Z. Zalisz, S. Krol, P. Nieslony, Invetgation of friction and wear mechanisms of the PVD-TiAlN coated carbide in dry sliding against steels and cast iron, Wear, 261 (2006), Pages 1191-1200.

[28] W. Hirst and J. K. Lancaster, Proc. R. Soc. Lond. A 6 December 1960 vol. 259 no. 1297, Pages 228-241.

[29] N. Saka, A.M. Eleiche and N. P. Suh, Wear 44, 109 (1977). 
[30] C. Yang and S. Bahadur, Friction and wear behaviour of alumina-based ceramics in dry and lubricated sliding against tool steel, Wear 157 (1992), Pages 263-277.

[31] N. C. Welsh, The dry wear of steels, Trans. Roy. Soc. London. 1965, Vol. 257.A, Pages 51-70.

[32] S.C. Lim, M.F. Ashby Overview no. 55 wear-mechanism maps, ActaMetallurgica 35 (1987), Pages 1-24.

[33] S. C. Lim, M. F. Ashby and J. H. Brunton, Wear-rate transitions and their relation to wear mechanism, ActaMetallurgica 35 (1987), Pages 1343-1348.

[34] L. C. Betancourt-Dougherty, R. W. Smith, Effects of load and sliding speed on the wear behaviour of plasma sprayed TiC-NiCrBSi coatings, Wear 217 (1998), Pages 147-154.

[35] M. Mustafa Yildirim, Soner Buytoz, Mustafa Ulutan, Dry sliding wear behaviour of TIG welding clad WC composite coatings, Applied Surface Science 252 (2005), Pages 1313-1323.

[36] S. Kataria, N. Kumar, S. Dash, A. K. Tyagi, Tribological and deformation behaviour of titanium coating under different sliding contact conditions, Wear 269 (2010), Pages 797-803.

\section{List of Table}


Table 1. The chemical composition of the 303 stainless steel disk

Table 2. The chemical composition of the 303 stainless steel base TiC coating disk surface

Table 3. Wear rate of uncoated 303stainless steel against alumina at constant sliding speeds and various normal loads

Table 4. Wear rate of uncoated 303SS at room temperature at constant normal loads and various sliding speeds

Table 5. Wear rate of TiC composite coating against alumina at constant sliding speeds and various normal loads

Table 6. Wear rate of $\mathrm{TiC}$ composite coating against alumina at constant normal loads and various sliding speeds

Table 7. The total mass loss of 303 stainless steel and TiC coating against alumina different constant

\section{List of Figure}


Fig. 1. a) Microstructure of 303 stainless steel 200X and b) EDX analysis of 303 stainless steel

Fig. 2. a) The microstructure of 303 stainless steel base $\mathrm{TiC}$ coating surface magnification $\mathrm{X} 500$ and $\mathrm{b}$ ) the EDX analysis of the 303 stainless steel base TiC coating

Fig. 3. SEM micrograph of the wear tracks, a) $2 \mathrm{~N}$ normal load and $3 \mathrm{~cm} \cdot \mathrm{s}^{-1}$ sliding speed, b) $4 \mathrm{~N}$ normal load and $7 \mathrm{~cm} \cdot \mathrm{s}^{-1}$ sliding speed, c) $4 \mathrm{~N}$ normal load and $11 \mathrm{~cm} \cdot \mathrm{s}^{-1}$ sliding speed and d) $8 \mathrm{~N}$ normal load and $15 \mathrm{~cm} \cdot \mathrm{s}^{-1}$ sliding speed

Fig. 4. EDX analysis of the wear tracks, a) $2 \mathrm{~N}$ normal load and $3 \mathrm{~cm} \cdot \mathrm{s}^{-1}$ sliding speed, b) $4 \mathrm{~N}$ normal load and $7 \mathrm{~cm} \cdot \mathrm{s}^{-1}$ sliding speed, c) $4 \mathrm{~N}$ normal load and $11 \mathrm{~cm} \cdot \mathrm{s}^{-1}$ sliding speed and d) $8 \mathrm{~N}$ normal load and $15 \mathrm{~cm} \cdot \mathrm{s}^{-1}$ sliding speed

Fig. 5. a) Wear rate vs normal load, b) Wear rate vs sliding speed of 303stainless steel against alumina

Fig. 6. SEM micrograph of the wear tracks, a) $2 \mathrm{~N}$ normal load and $3 \mathrm{~cm} \cdot \mathrm{s}^{-1}$ sliding speed, b) $8 \mathrm{~N}$ normal load and $3 \mathrm{~cm} . \mathrm{s}^{-1}$ sliding speed, c) $10 \mathrm{~N}$ normal load and $7 \mathrm{~cm} \cdot \mathrm{s}^{-1}$ sliding speed, d) $6 \mathrm{~N}$ normal load and $15 \mathrm{~cm} \cdot \mathrm{s}^{-1}$ sliding speed, e) $8 \mathrm{~N}$ normal load and $11 \mathrm{~cm} \cdot \mathrm{s}^{-1}$ sliding speed and f) $8 \mathrm{~N}$ normal load, and $7 \mathrm{~cm} \cdot \mathrm{s}^{-1}$ sliding speed

Fig. 7. EDX analysis of the wear tracks, a) $2 \mathrm{~N}$ normal load and $3 \mathrm{~cm} \cdot \mathrm{s}^{-1}$ sliding speed, b) $8 \mathrm{~N}$ normal load and $3 \mathrm{~cm} \cdot \mathrm{s}^{-1}$ sliding speed, c) $10 \mathrm{~N}$ normal load and $7 \mathrm{~cm} \cdot \mathrm{s}^{-1}$ sliding speed, d) $6 \mathrm{~N}$ normal load and $15 \mathrm{~cm} \cdot \mathrm{s}^{-1}$ sliding speed, e) $8 \mathrm{~N}$ normal load and $11 \mathrm{~cm} \cdot \mathrm{s}^{-1}$ sliding speed, and f) $8 \mathrm{~N}$ normal load and $7 \mathrm{~cm} \cdot \mathrm{s}^{-1}$ sliding speed

Fig. 8. a) Wear rate vs normal load, b) Wear rate vs sliding speed of TiC against alumina

Fig. 9. Wear trends and coefficient of friction comparison of 303 stainless steel and TiC coatings against alumina, a) wear trend of 303SS against alumina, b) coefficient of friction of 303SS against alumina, c) wear trend of TiC coatings against alumina, d) coefficient of friction of TiC coatings against alumina, e) coefficient of friction of 303SS against alumina for the range of normal loads and sliding speeds and f) ) coefficient of friction of $\mathrm{TiC}$ coatings against alumina for the range of normal loads and sliding speeds

Fig. 10. Wear rate comparison of 303 stainless steel and $\mathrm{TiC}$ coatings, a) at $3 \mathrm{cms}^{-1}$ sliding speed and various normal load, b) at $7 \mathrm{cms}^{-1}$ sliding speed and various normal load, c) at $11 \mathrm{cms}^{-1}$ sliding speed and various normal load and d) at $15 \mathrm{cms}^{-1}$ sliding speed and various normal load

Fig. 11. Total mass loss comparison of 303 stainless steel and303 stainless steel base TiC coating at each constant speed for the range of normal loads

Fig. 12. Optical Micrograph of wear tracks of TiC coating against alumina, 
a) $7 \mathrm{~cm} \mathrm{~s}^{-1}$ sliding speed and $10 \mathrm{~N}$ normal load, b) $11 \mathrm{~cm} \mathrm{~s}^{-1}$ sliding speed and $10 \mathrm{~N}$ normal load and c) $15 \mathrm{cms}^{-1}$ sliding speed and $10 \mathrm{~N}$ normal load

Fig. 13. The wear mode map, a) 303 stainless steel uncoated disk against alumina and b) TiC coating disk against alumina

Fig. 14: The wear mechanism map, a) 303stainless steel uncoated disk against alumina and b) TiC coating against alumina

Fig. 15: Wear mechanism map for 303 stainless steel disk against 8620 low alloy steel (from the previous work) 